\title{
Do plural ao singular: condições de gênero e carreira científica na área de engenharias da região Norte
}

\section{The plural to the singular: conditions of gender and scientific career in the area of engineering in Northern Region}

Ariane Serpeloni Tavares - Psicóloga e Mestre em Desenvolvimento Regional pela Universidade Federal do Tocantins/UFT. E-mail: ariane_st@icloud.com

Temis Gomes Parente - Doutora em História pela Universidaade Federal de Pernambuco/ UFPE, Pós-doutora pelo CEDEPLAR/UfMG, Professora do Programa de PósGraduação em Desenvolvimento Regional da UFT, Palmas. E-mail: temis.parente@uol. com.br

\section{Resumo}

Este artigo objetiva analisar a presença de mulheres no topo da carreira científica. Refletese sobre a participação das mulheres nas diversas etapas da construção de uma carreira, especialmente na área de Engenharias das universidades federais da região Norte, entre os anos de 2008 e 2012. Realizou-se a coleta de dados quantitativos via internet, principalmente por meio do Sistema Eletrônico do Serviço de Informação ao Cidadão (e-SIC). Os dados foram analisados e interpretados sob a perspectiva de gênero e mostram que o número de mulheres cai ao longo da trajetória científica, resultando em uma pequena representação feminina entre os bolsistas de produtividade, principalmente nas áreas consideradas masculinas. Os dados possibilitaram verificar que há disparidades regionais quanto a investimentos no sistema de pós-graduação e que isso pode ocasionar disparidades também em relação à participação das mulheres na ciência.

\section{Palavras-chave}

Gênero. Engenharia. Carreira cientifica. Bolsa de produtividade. Região Norte.

\begin{abstract}
This paper aims to examine the presence of women in scientific career. It reflects about women participation in various stages of the scientific career, especially in Engineering area of Federal Universities at Northern Region, between the years of 2008 and 2012. The quantitative data were collected from the Internet, mainly through Citizens Information Service Electronic System (e-SIC). These data, which were analyzed and interpreted using gender perspective, show that the number of women falls along the scientific path, resulting in a small female representation among productivity scholars, especially in areas considered as masculine. The data allow us to verify that there are regional disparities in investment in postgraduate system and it can also lead to disparities on women's participation in science.
\end{abstract}

\section{Keywords}

Gender. Engineering. Scientific career. Productivity grant. Northern Region. 


\section{INTRODUÇÃO}

Este artigo traz resultados e análises decorrentes da pesquisa realizada durante o mestrado em Desenvolvimento Regional da Universidade Federal do Tocantins, concluído em 2014. Utilizando a perspectiva de gênero ${ }^{1}$, teve-se como objetivo retratar e refletir sobre a baixa presença das mulheres nas posições de prestígio científico ${ }^{2}$ nas universidades federais da região Norte, em especial nas "ciências duras", como é o caso das Engenharias. A pesquisa utilizou a abordagem quantitativa de coleta de dados, buscando produzir um panorama estatístico do fenômeno estudado. Expressar as questões de gênero em números foi possível porque, segundo Gamba (2008), as desigualdades de gênero ${ }^{4}$ produzem e reproduzem a discriminação, tornando-se concretas nos mais diversos âmbitos, como no trabalho, na família, na política, na ciência, nas organizações, ou seja, na cultura de forma geral.

As questões de gênero, portanto, não deixariam de influenciar a participação e ascensão das mulheres no âmbito científico. Quando se fala em carreira científica, imagina-se que o topo corresponda ao reconhecimento pelo desenvolvimento de uma nova teoria, pela invenção de um produto revolucionário ou pela descoberta de um novo material. Embora o reconhecimento por estes feitos seja um sinal de sucesso para um cientista, verifica-se que muitas mulheres que estiveram por trás ou à frente de grandes descobertas não receberam os méritos pelo seu trabalho. As mulheres não estão, por exemplo, em proporção justa entre os ganhadores de prêmios Nobel ou entre os cientistas da Associação Brasileira de Ciências (MELO; CASEMIRO, 2003; LETA, 2003; SCHIEBINGER, 2001). Assim, compreende-se que o sucesso e a ascensão na carreira científica não são lineares, mas sim enviesados pelas questões de gênero e de poder.

Entretanto, para fins metodológicos e para que se tivesse parâmetros objetivos, considerou-se, neste trabalho, que o topo da carreira científica corresponde ao reconhecimento através de Bolsas de Produtividade em

1 Adotar uma perspectiva de gênero, segundo Gamba (2008), consiste em optar por uma concepção epistemológica, compreendendo a realidade a partir do olhar do gênero e das relações de poder.

2 Prestígio científico, neste trabalho, refere-se ao recebimento de bolsas de produtividade em pesquisa do CNPq.

3 O termo "ciências duras", ou hard sciences, é utilizado para denominar o grupo de áreas do conhecimento relacionadas com as ciências exatas, tecnológicas e engenharias. Já as áreas de humanidades e sociais, são chamadas de "ciências moles" ou soft sciences.

4 A definição de gênero empregada neste trabalho é a proposta pela historiadora americana Joan Scott, segundo a qual "...o gênero é um elemento constitutivo de relações sociais fundadas sobre as diferenças percebidas entre os sexos...", sendo também “... um primeiro modo de dar significado às relações de poder" (SCOTT, 1990, p. 14). 
Pesquisa - PQ 5 do Conselho Nacional de Desenvolvimento Científico e Tecnológico (CNPq). As etapas da carreira científica consideradas no levantamento de dados foram a graduação, o mestrado, o doutorado, a docência em programas de pós-graduação stricto sensu e o enquadramento como bolsista produtividade pelo CNPq. Os dados restringiram-se a cursos presenciais das universidades federais entre 2008 e $2012^{6}$, tendo como foco a região Norte e os cursos da área de Engenharias ${ }^{7}$, que foi escolhida por representar de forma mais contundente o impacto das questões de gênero em seus mais diversos aspectos.

Os documentos que compuseram a base de dados da pesquisa foram coletados de forma eletrônica, sendo considerados dados secundários. As informações completas dos Censos da Educação Superior 1991-2012 (INEP, 2013a) e dos cursos de pós-graduação stricto sensu 2004-2012 (CAPES, 2013) foram reunidas pelos órgãos federais responsáveis e fornecidas por meio de solicitação realizada pelas pesquisadoras no Sistema Eletrônico do Serviço de Informação ao Cidadão (e-SIC) ${ }^{8}$. Os demais dados foram obtidos por meio de informações oficiais contidas em sites da internet, englobando informações sobre bolsas de estudos (CNPQ, 2013a); bolsistas de produtividade em pesquisa (CNPQ, 2013b); composição dos Comitês de Assessoramento (CNPQ, 2013e); membros da Academia Brasileira de Ciências (ABC, 2013); dados sobre grupos de pesquisa (CNPQ, 2013b); perfil dos pesquisadores (CNPQ, 2013d); e investimentos em CT\&I (CNPQ, 2013f).

As pesquisas sobre a presença da mulher no ensino superior e na ciência mostram que, nos últimos anos, tem ocorrido um aumento da presença feminina nos cursos de graduação e em postos de pesquisa, entretanto, algumas limitações ainda se apresentam: as mulheres permanecem concentradas em cursos das áreas de humanas e sociais - ou soft sciences -, que são menos valorizadas socialmente, e continuam enfrentando dificuldades de acesso a cargos de liderança e/ ou maior prestígio (MELO, 2008; RISTOFF, 2008; TAVARES, 2008; YANNOULAS, 2007).

5 A Bolsa de Produtividade em Pesquisa do CNPq foi concebida como uma forma de incentivo aos pesquisadores detentores de título de doutorado e de destacada produção científica, para valorização de seu trabalho e dedicação frente a seus pares.

6 Para evitar distorções, trabalhou-se com a média do período de 2008 a 2012, pois muitos dados não apresentam um comportamento linear de aumento ou redução, mas sim oscilações consideráveis entre os anos.

7 Corresponde às áreas de avaliação da Coordenação de Aperfeiçoamento de Pessoal de Nível Superior (CAPES) denominadas Engenharias I, II, III e IV, bem como os cursos de graduação relacionados.

8 Por meio do endereço http://www.acessoainformacao.gov.br pode-se solicitar informações para órgãos, entidades e empresas do Poder Executivo Federal. Esta ferramenta visa atender à Lei Federal 12.527, de 18 de novembro de 2011, e teve bastante utilidade neste trabalho. 
Estas mesmas questões foram encontradas na pesquisa, por meio da qual se demonstra que, apesar da grande presença de mulheres na graduação, estas se concentram em áreas tipicamente femininas e vão se tornando cada vez mais raras ao longo das etapas da carreira científica. Em casos extremos, como na área de Engenharias das Universidades federais da região Norte, não há pesquisadoras - no plural - com bolsa produtividade, mas sim apenas uma pesquisadora - no singular. Ou seja, as questões de gênero, somadas às condições de desenvolvimento regional, fazem com que o plural de mulheres na base da carreira científica torne-se singular no topo.

\section{CONDIÇÕES DE GÊNERO E CARREIRA CIENTÍFICA}

Os estudos sobre o tema ciência e condições de gênero apontam que fatores históricos contribuíram para que a ciência adquirisse um caráter androcêntrico, afastando as mulheres de sua prática. De acordo com Schiebinger (2001), desde a profissionalização da ciência e a institucionalização das universidades, no período da revolução industrial, a atividade científica, que era desenvolvida também por mulheres, deixou de lhes ser permitida. Nesta época, em que houve uma evidente separação entre as esferas do público e do privado, a ciência passou a ser vinculada ao espaço público e ao masculino, sendo oferecidas poucas oportunidades para que as mulheres estudassem nas universidades e se dedicassem à atividade científica.

Com o tempo, o acesso das mulheres às universidades e à atuação na área científica passaram a ser permitidos. Entretanto, segundo Yannoulas (2007), mesmo decorrido um longo período de participação das mulheres na área científica, permanecem circulando estereótipos quanto à capacidade das mulheres para a ciência, como a dificuldade para lidar com tarefas objetivas e abstratas, falta de localização espaço-temporal, defasagem na compreensão da lógica científica, entre outros.

De acordo com Kergoat (2009), a divisão sexual do trabalho, moldada social e historicamente, fez com que se designasse às mulheres as atividades da esfera doméstica, relacionadas à reprodução social e não remuneradas, enquanto aos homens couberam as atividades do espaço público, de maior prestígio social. Esta divisão se reflete na inserção profissional das mulheres, que ainda se dedicam a profissões consideradas adequadas aos estereótipos femininos de submissão e delicadeza, com menor remuneração e status social. Segundo Viana (2013), 
devido aos estereótipos de gêneros, as mulheres são geralmente associadas a atividades como alimentação, maternidade, cuidado e educação.

Essa "aptidão" das mulheres para algumas profissões começa a ser moldada e reforçada na infância, quando a socialização de gênero diz quais são as atividades e as habilidades esperadas de meninas e meninos, limitando as escolhas profissionais e a autoconfiança das meninas quanto à sua capacidade de envolverse em atividades científicas e tecnológicas (SAAVEDRA, 2009).

Os dados coletados na pesquisa mostram que, apesar de um expressivo aumento da participação das mulheres no ensino superior e na pós-graduação - o que pode ser considerado um avanço - há a tendência à permanência das mulheres em profissões historicamente consideradas femininas, ou seja, relacionadas ao cuidado, à assistência, e ao ensino de nível básico.

Na região Norte, o percentual de mulheres entre os alunos matriculados em cursos de graduação nas universidades federais passou de 51\% em 1991, para 54\% em 2012 (INEP, 2013). Verifica-se também um aumento da participação das mulheres no mestrado, em que passam de 49\% dos alunos em 2004, para 54\% em 2012 (CAPES, 2013). No doutorado, apesar de algumas oscilações ao longo do período, a participação das mulheres vem mantendo-se em linha ascendente desde 2009, sendo que atingiram, em 2012, o percentual de 50\% dos discentes de doutorado nas universidades federais do Norte (CAPES, 2013).

Apesar do aumento da presença feminina entre matriculados e concluintes nos diversos níveis educacionais, a participação das mulheres não se dá de forma homogênea em todas as áreas do conhecimento. Nas universidades federais da região Norte, no período entre 2008 e 2012, a grande área de conhecimento que mais concentra mulheres, na graduação, é a de Letras, Linguística e Artes, em que as mulheres correspondem a 69\% dos alunos. Os cursos de mestrado em que há maior concentração de mulheres são os das áreas de Ciências da Saúde, em que as mulheres representam $71 \%$ dos alunos matriculados e os da área de Letras, Linguística e Artes, que detêm 70\% de mulheres entre os discentes. No doutorado, as mulheres estão mais presentes nos cursos das áreas de Ciências Humanas, em que são 60\% dos alunos, e em Ciências Sociais Aplicadas e Ciências da Saúde, ambas com 59\% de mulheres. Já os homens concentram-se, da graduação à pós-graduação, em cursos das áreas de Engenharias e de Ciências Exatas e da Terra (INEP, 2013; CAPES, 2013).

Pode-se compreender que estes dados estão relacionados às condições de gênero, que levam homens e mulheres a optarem por cursos de graduação em algumas áreas e não em outras. Embora as influências se exerçam sobre as escolhas de ambos os sexos, isto se dá de forma diferenciada, pois as 
profissões reservadas às mulheres, em sua maioria, são profissões ligadas à esfera privada e, portanto, menos valorizadas socialmente (BOURDIEU, 2002; KERGOAT, 2009).

Costa e Yannoulas (2011) consideram que os princípios da divisão sexual do trabalho (separação e hierarquização) aplicam-se também ao campo científico, sendo que neste há a divisão sexual do conhecimento. O princípio da separação se expressa por meio da divisão de homens e mulheres entre as áreas do conhecimento. Já a hierarquização pode ser verificada pela diferente valoração das áreas consideradas femininas e as consideradas masculinas. Ou seja, as áreas com predominância de mulheres são, geralmente, consideradas menos importantes do que as áreas em que há maior concentração de homens.

O que chama a atenção, entretanto, é que as condições de gênero não impactam apenas na escolha da profissão. As questões de gênero acompanham as mulheres ao longo de toda a carreira, seja científico-acadêmica ou não. De acordo com Rossiter (1982), além da segregação horizontal - que faz com que as mulheres concentrem-se nas áreas de Humanidades, há a segregação vertical que faz com que, a cada degrau rumo às posições de prestígio, menor seja a ocorrência de mulheres. Esta dificuldade de subir os diversos degraus da carreira faz com que as mulheres sejam mais raras do que os homens em posições de comando e de alto reconhecimento.

O Gráfico 1 demonstra que nas universidades federais da região Norte, embora as mulheres sejam maioria dentre os matriculados nos cursos de graduação (53\%) e até mesmo de mestrado (54\%), passam a ser minoria a partir do doutorado (49\%). O quadro se agrava ainda mais quando se observa que apenas 33\% dos professores dos cursos de mestrado e doutorado são mulheres, e que somente $27 \%$ das bolsas de produtividade são destinadas a elas.

Um fato que torna ainda mais evidente a segregação vertical são as discrepâncias entre os níveis das bolsas produtividade ${ }^{9}$ fornecidas pelo $\mathrm{CNPq}$ a docentes homens e mulheres. Nas universidades federais da região Norte, enquanto as mulheres são beneficiadas com 30\% das bolsas de nível 2 - ou seja, as de menor valor - apenas 11\% recebem as bolsas de nível $1 \mathrm{~A}$ (CNPq, 2013f).

\footnotetext{
As bolsas produtividade são fornecidas em sete níveis diferentes, sendo o nível mais elevado o Sr, seguido pelo 1A, 1B, 1C, 1D, 2 e 2F. Os pesquisadores são avaliados de acordo com a produtividade pelos Comitês de Assessoramento, compostos por outros pesquisadores.
} 
Gráfico 1 - Percentual médio de matriculados e concluintes de cursos de graduação/mestrado/doutorado, professores de pós-graduação das universidades federais da região Norte e bolsistas produtividade, por sexo, no período de 2008 a 2012 .

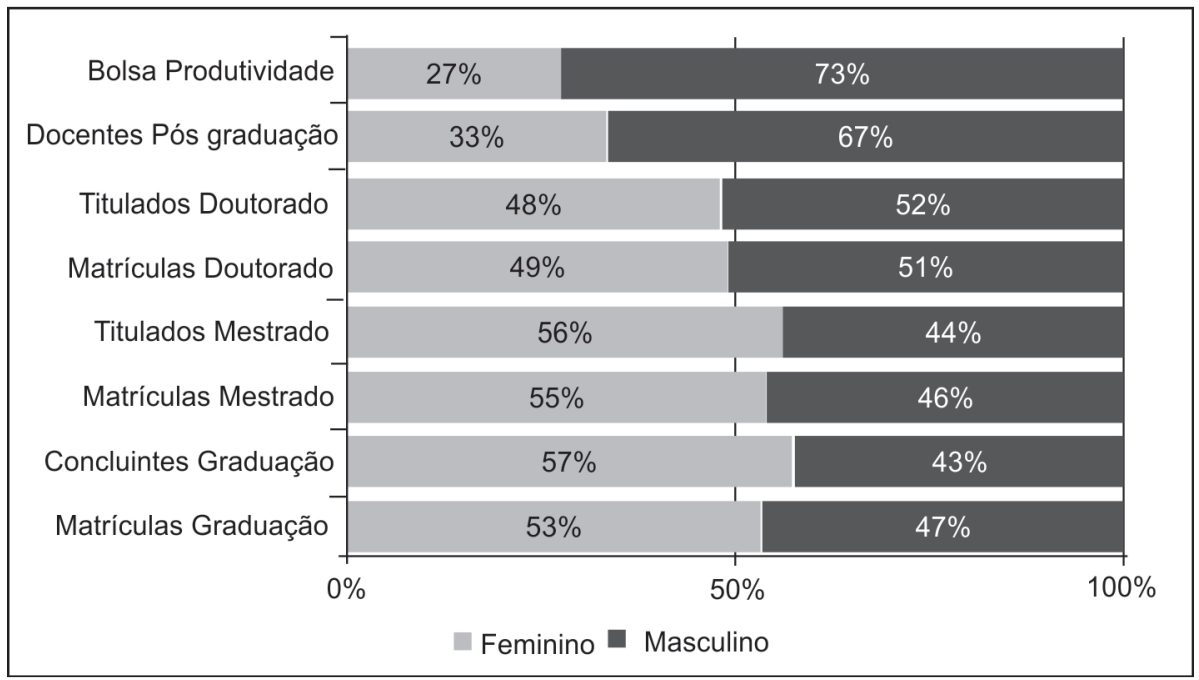

Fonte: Elaboração das autoras, a partir de dados de 2008 a 2012 - INEP (2013a), CAPES (2013) e CNPq (2013a).

Ao analisar os dados coletados na presente pesquisa, verifica-se que a segregação vertical, mais acentuadamente em algumas áreas do conhecimento, ocorre em todas, mesmo nas consideradas femininas. $\mathrm{Na}$ área de Ciências Humanas - a segunda área com maior número de matrículas de mulheres na graduação, e, portanto, uma área majoritariamente feminina - tem-se $66 \%$ de mulheres entre os discentes de graduação, $58 \%$ entre os alunos de mestrado e $60 \%$ entre os matriculados no doutorado. Entretanto, as mulheres são somente $46 \%$ dos professores dos programas de mestrado e doutorado e $35 \%$ dos bolsistas produtividade (INEP, 2013a; CAPES, 2013; CNPq, 2013a). Ou seja, o percentual de mulheres no topo corresponde a um pouco mais da metade do percentual de mulheres na graduação.

Nas áreas de Engenharias, Ciências Exatas e da Terra e Ciências Agrárias, que são áreas consideradas masculinas, a redução ao longo da carreira acadêmica ocorre de forma ainda mais acentuada do que nas áreas femininas, resultando em uma quantidade maior de homens com bolsas para financiamento de pesquisa. No caso das Engenharias, o percentual de mulheres no topo da carreira (9\%) é menos de um terço do percentual verificado na graduação, que é de 28\% (INEP, 2013a; CAPES, 2013; CNPq, 2013a). 
Desta forma, verifica-se que em todas as áreas, mesmo naquelas em que as mulheres têm maior representatividade na graduação, e que são consideradas áreas femininas, os homens são maioria quando se trata de reconhecimento e financiamento de pesquisa. A baixa presença de mulheres nas ciências duras tem suas causas relacionadas aos dois tipos de segregação: a horizontal, que as afasta destas áreas e a vertical, que dificulta o prosseguimento na carreira.

\section{ENGENHARIAS: UMA ÁREA MASCULINA}

Algumas áreas do conhecimento, dentre elas a de Engenharias, são majoritariamente masculinas devido às relações de gênero, que estão imersas em um contexto histórico e social. Segundo Lombardi (2006), o fato de a Engenharia ter-se originado do contexto militar - uma instituição masculina constitui um importante fator explicativo para a predominância de homens entre os profissionais da área. Além disso, é uma profissão bem remunerada e com alto status social, sendo, em decorrência disso, um reduto masculino.

Apesar de, por muito tempo, as mulheres estarem ausentes dos cursos de Engenharia, pode-se observar um aumento gradativo da presença delas entre os alunos e os profissionais. Segundo Lombardi (2006), este fato está relacionado a alguns fatores que contribuíram para mudanças no campo de trabalho da engenharia e na categoria profissional dos engenheiros nas décadas de 1980 e 1990, como: a consolidação do aumento da escolaridade das mulheres brasileiras, resultando na ampliação de suas possibilidades de escolha profissional; a expansão da oferta de matrículas nos cursos de Engenharia; a ampliação da especialização dos cursos, produzindo efeitos sobre o emprego e remuneração da profissão e acentuando a segmentação interna; e as mudanças que afetaram a economia e o mercado de trabalho.

Entre 1991 e 2012 as mulheres passaram de 17\% para 30\% dos alunos de graduação da área de Engenharias nas universidades federais da região Norte (INEP, 2013). Este crescimento pode ser atribuído, assim como argumentado por Lombardi (2006), às maiores oportunidades de acesso aos cursos devido à expansão do sistema de ensino superior, que também ocorreu na região Norte nas últimas décadas.

Na pós-graduação stricto sensu, os dados coletados acerca do período de 2004 a 2012, mostram uma leve tendência de aumento da participação das mulheres dentre os alunos matriculados, porém não no mesmo ritmo de crescimento das 
discentes de graduação. A presença das mulheres dentre os docentes de pósgraduação stricto sensu, na área de Engenharias das universidades federais da região Norte vem mantendo-se em linha ascendente desde 2008, passando de 11\% no referido ano para 16\% em 2012 (CAPES, 2013).

O que se verifica é que apesar da maior entrada de mulheres nos cursos de graduação nos últimos anos, ainda não se observa um crescimento no mesmo ritmo da presença das mulheres entre os discentes de pós-graduação, nem entre os docentes destes cursos, o que nos mostra que há barreiras para o crescimento profissional das mulheres em todas as etapas do desenvolvimento da carreira.

Esta segregação vertical pode ser verificada com clareza no Gráfico 2, que mostra os percentuais de mulheres ao longo da carreira acadêmico-científica, na área de Engenharias das universidades federais da região Norte.

Gráfico 2 - Percentual médio de matriculados e concluintes de cursos de graduação/mestrado/doutorado, professores de pós-graduação das universidades federais da região Norte e bolsistas produtividade da área de Engenharias, por sexo, no período de 2008 a 2012.

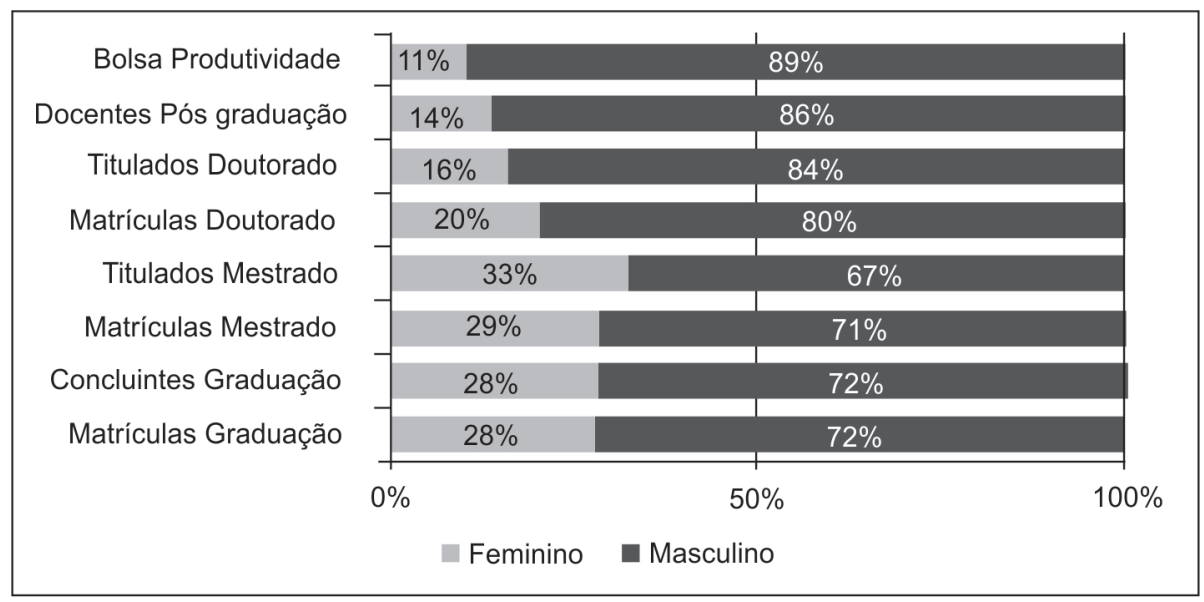

Fonte: Elaboração das autoras, a partir de dados de 2008 a 2012 - INEP (2013a), CAPES (2013) e CNPq (2013a).

A área de Engenharias é onde se encontra menos mulheres em todos os níveis da carreira. Nesta área observa-se uma elevação do percentual de mulheres tituladas no nível de mestrado (33\%) em relação às graduadas $(28 \%)$ e também em relação às matriculadas naquele nível (29\%). Entretanto, a participação das mulheres diminui nos cursos de doutorado para $20 \%$ dos matriculados e $16 \%$ dos titulados (INEP, 2013a; CAPES, 2013; CNPq, 2013a). Uma possível razão para a desistência dos homens durante os cursos de mestrado é a maior facilidade 
que encontram para se inserir no mercado de trabalho. Já a menor titulação de mulheres no doutorado pode estar relacionada a questões de gênero como a maternidade, por exemplo.

Quando se analisa o topo da carreira, verifica-se que na área de Engenharias das universidades federais do Norte, na média do período de 2008 a 2012, 11\% das bolsas de produtividade em pesquisa foram destinadas a pesquisadoras. Em 2012, o percentual era de 13\%, o que representa a quantidade de duas bolsas. Em 2008 havia apenas uma bolsa, e em 2009 não havia nenhuma bolsa produtividade para mulheres na área de Engenharias na região Norte. No ano de 2013, entretanto, havia apenas uma bolsista produtividade na área de Engenharias, quadro que se manteve em nova consulta realizada ao banco de dados em 07.08.2014 (CNPq, 2013a; 2013c).

Este quadro nos leva a perceber que as mulheres vão se tornando cada vez mais raras a cada degrau da carreira científica, o que faz com que no topo, na área de Engenharias da região Norte, haja apenas uma. O plural tornou-se singular. É importante acrescentar que o número de bolsistas produtividade não aumenta quando se verifica a existência de bolsas produtividade para além do âmbito das universidades federais. Em outros institutos de pesquisa e instituições estaduais da região Norte também não há outra mulher pesquisadora da área de Engenharias que recebe bolsa produtividade em pesquisa ou bolsa de desenvolvimento tecnológico (CNPq, 2013c).

Após analisar os dados expostos, cabe perguntar a respeito do componente regional. Compreende-se que a queda da participação das mulheres conforme se sobe na hierarquia não é uma exclusividade da região Norte, tampouco é um fenômeno que ocorre apenas no Brasil. Mas esta realidade se faz presente nas outras regiões geográficas de forma mais ou menos acentuada? As condições de desenvolvimento e de investimento em ensino e pesquisa na região Norte podem servir como agravantes para as disparidades de gênero?

\section{UMA QUESTÃO DE LOCALIZAÇÃO GEOGRÁFICA?}

A região Norte foi a que recebeu o menor percentual de investimentos, na forma de bolsas de fomento à pesquisa, realizados pelo CNPq e fundos setoriais no período de 2000 a 2010. É também a região que recebeu menor investimento per capita, entre 2000 e 2012 (CNPq, 2013f). Este baixo investimento no sistema de pós-graduação e na pesquisa da região Norte, na forma de bolsas de fomento, pode estar relacionado à extrema carência de doutores na região, onde se tem 
apenas 24,9 doutores por 100 mil habitantes, um número bastante inferior ao das demais regiões ${ }^{10}$ (CNPq, 2013f).

Segundo o documento do Plano Nacional de Pós-Graduação (PNPG) 2011, o sistema de Ciência Tecnologia e Inovação (CT\&I) da região Norte encontra-se subdimensionado, não tendo a força e tamanho necessários para alavancar o seu desenvolvimento econômico e social, sendo que a região tem contribuído mais com a CT\&I nacional do que tem recebido da União (BRASIL, 2010).

Na região Norte, até o nível de mestrado, as mulheres se fazem presentes em percentual maior do que o verificado no âmbito nacional. Entretanto, após esta etapa verifica-se que há maior equidade entre mulheres e homens no âmbito nacional do que o observado na região Norte (INEP, 2013a; CAPES, 2013; CNPq 2013a).

A hipótese para a ocorrência deste fenômeno, ou seja, para a queda do percentual de mulheres no doutorado, é a de que há menores oportunidades de cursar doutorado na região Norte, o que afetaria de forma mais contundente a presença das mulheres do que a dos homens no referido nível de ensino. Nas universidades federais da região Norte, na soma dos anos de 2008 a 2012, havia 20.247 alunos matriculados no mestrado e somente 6.589 no doutorado, ou seja, um aluno de doutorado para três de mestrado, aproximadamente. No âmbito nacional havia, neste período, quase duas vagas de doutorado para cada três de mestrado (CAPES, 2013).

A queda no número de vagas se mostra de forma ainda mais clara quando se analisa a área de Engenharias. Nesta, as regiões Centro-Oeste e Norte têm o menor percentual de mulheres nos cursos de doutorado ${ }^{11}$, com $27 \%$ e $20 \%$, respectivamente. Também são estas regiões as que têm a menor quantidade de alunos de doutorado para cada discente de mestrado na área de Engenharias das universidades federais, com 0,34 e 0,29 vagas de doutorado por vaga de mestrado, respectivamente. Na região Sul, por exemplo, há 0,58 vagas de doutorado para cada vaga de mestrado, sendo que nesta região observa-se o percentual de $32 \%$ de mulheres entre os alunos de doutorado, um percentual bastante superior ao encontrado na região Norte (CAPES, 2013).

Pode-se compreender, com base nestes dados, que quanto menores as oportunidades de acesso, menor a participação das mulheres nos cursos de doutorado. As oportunidades de realização de mestrado na área de Engenharias

10 Nas regiões Sudeste e Sul, têm-se, respectivamente, 56,4 e 66,3 doutores/100mil habitantes.

11 No Centro-Oeste há nove programas de doutorado na área de Engenharias das universidades federais, localizados em apenas duas cidades (Brasília/DF e Campo Grande/MS), semelhante à situação encontrada no Norte: dois programas, mas apenas em uma cidade (Belém/PA). 
nas universidades federais da região Norte estão divididas entre três estados: Amazonas, com quatro cursos; Pará, com seis cursos e Tocantins com um curso. Já as oportunidades de realização de doutorado se restringem ao estado do Pará e, ainda mais, a uma cidade: Belém/PA. Assim, as oportunidades para os titulados em mestrado cursarem doutorado na área de Engenharias se reduzem consideravelmente, tanto pela queda no número de vagas e de especialidades, quanto pela concentração geográfica dos cursos.

As distâncias percorridas na região Norte, bem como as condições das estradas e a pequena quantidade de aeroportos são questões que se apresentam de forma mais acentuada em comparação com as demais regiões. Assim, diferentemente do que ocorre em outros locais, a maior parte das cidades do Norte está a longas distâncias dos locais onde há cursos de doutorado, o que torna as viagens demoradas. Em alguns casos, pode ser mais fácil deslocar-se para estudar em outras regiões do que dentro do próprio Norte.

Desta forma, as restrições para se cursar doutorado na região Norte podem estar contribuindo para que um percentual elevado de mulheres pare estudos no nível de mestrado. Não se pretende, com isso, afirmar que estas dificuldades impostas pelas condições da região não se apresentem também aos homens, mas sim que se colocam de forma muito mais forte para as mulheres, principalmente em decorrência do papel social que lhes é atribuído (cuidado da casa, dos filhos etc.).

Da mesma maneira como são poucas as mulheres matriculadas no nível de doutorado, também são raras as professoras em cursos de pós-graduação. A região Norte figura como o local onde há a menor proporção de mulheres atuando como docentes nos programas de mestrado e doutorado na área de Engenharias das universidades federais: enquanto na região as mulheres são 14\% dos docentes destes programas, em nível nacional o percentual é de 19\%, na média entre 2008 e 2012 (CAPES, 2013).

Este fato merece ser analisado tanto com relação às causas como aos efeitos, que parecem formar um ciclo vicioso. Os fatores que podem levar a um menor número de docentes mulheres estão relacionados às menores oportunidades que as mulheres tiveram de cursar os níveis necessários, bem como das dificuldades de ascensão profissional. Esta menor presença de mulheres entre as docentes também pode levar à redução das discentes destes programas, que se tornam extremamente masculinos e, portanto, mais aversivos para mulheres. Além disso, a ausência de docentes do sexo feminino faz com que faltem exemplos de sucesso que inspirem e estimulem as alunas a continuarem, bem como pode elevar a tendência a preconceitos na seleção dos alunos. 
Os dados analisados, portanto, mostram que há disparidades regionais quanto à participação das mulheres, principalmente nos níveis mais elevados da trajetória acadêmica. Também levam a considerar que a condição das mulheres pesquisadoras na região Norte é influenciada tanto pelas relações de gênero quanto pelas condições regionais de desenvolvimento, principalmente em relação ao sistema de pós-graduação. Assim, as condições de gênero e o nível de desenvolvimento se somam, levando a condições desfavoráveis ao desenvolvimento da carreira científica das mulheres no Norte.

\section{CONSIDERAÇÕES FINAIS}

Por meio dos dados coletados pôde-se verificar que as questões de gênero, que começam a exercer influência desde a infância, levam as mulheres a se concentrarem em algumas profissões, social e historicamente vinculadas ao feminino, e afastarem-se de outras áreas do conhecimento, como a de Engenharias. Pôde-se verificar também, que, independentemente de terem concluído a graduação em cursos considerados femininos ou masculinos, a ascensão das mulheres em suas carreiras acadêmicas também sofre influência das questões de gênero, que tornam o caminho rumo ao topo muito mais difícil e lento para as mulheres. Estes dois efeitos das condições de gênero sobre a carreira das mulheres foram denominados segregação horizontal e vertical por Rossiter (1982).

Para que se eleve a presença das mulheres na ciência deve-se atuar sobre os dois tipos de segregação. Tabak (2006) aponta como possíveis ações para o estímulo da participação das mulheres na ciência: o incentivo à ciência em si; uma educação básica de qualidade, com a consciência de gênero, sem excluir as meninas; a garantia de creches e de serviços de cuidado para as crianças em congressos; subsídios de reinserção de mulheres que tenham se desvinculado da atividade científica por motivos familiares; sistemas de cota para mulheres no financiamento de projetos e bolsas de estudos no país e no exterior, dentre outras ações.

Neste sentido, há políticas e iniciativas vindas da Secretaria de Políticas para as Mulheres ${ }^{12}$ que têm o intuito de elevar a participação das mulheres nas ciências. Estas iniciativas, apesar de muito positivas, ainda se mostram com

12 Ver: Chamada Pública no 18/2013, intitulada "Meninas e Jovens Fazendo Ciências Exatas, Engenharias e Computação" (BRASIL, 2013) bem como o Programa Mulher e Ciência, disponível em: <http://www.cnpq.br/web/guest/apresentacao2>. 
pequeno poder de gerar mudanças. Outras políticas precisam ser adotadas para diminuir as barreiras que afastam as mulheres das áreas de exatas e de tecnologia, bem como as barreiras que reduzem as chances delas continuarem e chegarem a posições de prestígio científico.

Ainda, baseado nas interpretações dos dados da presente pesquisa tornase visível a necessidade de ampliação das vagas, dos cursos e das especialidades de mestrado e doutorado nas áreas tecnológicas, especialmente na região Norte, a fim de que as mulheres tenham maiores chances de prosseguir na carreira acadêmica. Uma questão importante, por exemplo, é que o maior programa de mestrado e doutorado na área de Engenharias - o de Engenharia Elétrica da UFPA - é um dos ramos mais "masculinos" da engenharia naquela instituição. Assim, cursos de pós-graduação em outros ramos onde já se tem maior presença de mulheres, como a Engenharia Civil, poderiam ser alvo de expansão.

Não se pode dizer, entretanto, que esta seria uma medida suficiente, dada a persistência dos padrões de discriminação de gênero. É importante compreender que as relações de gênero estão na base das desigualdades apontadas, devendose, cada vez mais, implementar programas e políticas que visem diminuir os estereótipos de gênero, desde a primeira infância.

\section{REFERÊNCIAS}

ABC - Academia Brasileira de Ciências. Membros Associados, 2013. Disponível em: <http://www.abc.org.br/rubrique.php3?id_rubrique=54>. Acesso em: 26 set. 2013.

BOURDIEU, P. A dominação masculina. 2. ed. Rio de Janeiro: Bertrand Brasil, 2002.

BRASIL. Ministério da Educação. Coordenação de Aperfeiçoamento de Pessoal de Nível Superior. Plano Nacional de Pós-Graduação - PNPG 2011-2020, v. 1, Brasília/DF: CAPES, 2010. Disponível em: < http://www.capes.gov.br/ sobre-a-capes/plano-nacional-de-pos-graduacao/pnpg-2011-2020>. Acesso em: 17 set. 2013 .

BRASIL. Chamada Pública MCTI/CNPq/SPM-PR/Petrobras nº 18/2013. Meninas e Jovens Fazendo Ciências Exatas, Engenharias e Computação, 2013. Disponível em: <http://www.cnpq.br/web/guest/chamadas-publicas?p_p_ $\mathrm{id}=$ resultadosportlet_WAR_ resultadoscnpqportlet_INSTANCE_0ZaM\&filtro $=$ resultados\&detalha $=$ chamadaDetalhada\&exibe $=$ exibe\&idResultado $=47-227$ 2064\&id=47-227-2064>. Acesso em: 11 mar. 2014. 
CAPES - Coordenação de Aperfeiçoamento de Pessoal de Nível Superior. Dados personalizados referentes a matriculados, titulados e docentes da pós-graduação stricto sensu, de 2004 a 2012, 2013. Recebido em: set. 2013.

CNPq - Conselho Nacional de Desenvolvimento Científico e Tecnológico. Ferramenta DataMart de Investimentos em CT\&I, 2013a. Disponível em: $<$ http://fomentonacional.cnpq.br/dmfomento/home/fmthome.jsp?>. Acesso em: out. 2013.

Diretório de Grupos de Pesquisa. 2013b. Disponível em: <http:// dgp.cnpq.br/censos/>. Acesso em 25 set 2013.

Mapa de Investimentos - Bolsistas de Produtividade em Pesquisa e Desenvolvimento Tecnológico. 2013, 2013c. Disponível em: <http:// efomento.cnpq.br/efomento/distribuicaoGeografica/distribuicaoGeografica. do?metodo=apresentar $>$. Acesso em: 19 ago. 2013.

Painel Lattes. 2013d. Disponível em: <http://estatico.cnpq.br/ painelLattes/>. Acesso em: 03 out. 2013.

Membros dos Comitês de Assessoramento. 2013e. Disponível em: <http://www.cnpq.br/web/guest/membros-dos-comites\#membros>. Acesso em: 26 ago. 2013.

Séries Históricas. 2013f. Disponível em: <http://www.cnpq.br/web/ guest/series-historicas>. Acesso em 30 set. 2013.

COSTA, A. C. da; YANNOULAS, S. C. Construindo novos túneis: subterfúgios das engenheiras para deslocar as fronteiras da divisão sexual da ciência e da tecnologia. INTERthesis, Florianópolis, v. 8, n. 2, p. 36-56, jul./dez. 2011. Disponível em: < https://periodicos.ufsc.br/index.php/interthesis/article/ view/1807-1384.2011v8n2p36>. Acesso em: 27 set. 2013.

GAMBA, S. ¿Qué es la perspectiva de género y los estudios de género?, 2008. Disponível em: <http://www.mujeresenred.net/spip.php?article1395>. Acesso em: 11 abr. 2014.

HIRATA, H; KERGOAT, D. Paradigmas sociológicos e categoria de gênero. Que renovação aporta a epistemologia do trabalho? Novos Cadernos NAEA, v. 11, n. 1, p. 39-50, jan-jun. 2008

INEP - Instituto Nacional de Estudos e Pesquisas Educacionais Anísio Teixeira.

Dados personalizados dos Censos da Educação Superior de 1191 a 2012, 2013a. Recebido em: out. 2013. 
KERGOAT, D. Divisão sexual do trabalho e relações sociais entre os sexos. In: HIRATA, H. et al. (Org.). Dicionário crítico do feminismo. São Paulo: Unesp, 2009. p. 67-75.

LETA, J. As mulheres na ciência brasileira: crescimento, contrastes e um perfil de sucesso. Estudos Avançados, São Paulo, v. 17, n. 49, p. 271-284, set./ dez. 2003. Disponível em: <http://www.scielo.br/scielo.php?script=sci_ arttext\&pid=S0103-40142003000300016> . Acesso em: 24 set. 2013.

LOMBARDI, M. . A engenharia brasileira contemporânea e a contribuição das mulheres nas mudanças recentes do campo profissional. Revista Tecnologia e Sociedade, Curitiba, n. 2, p. 109-131, 1. sem. 2006. Disponível em: <file:/ / C:/ Users/Usuario/ Downloads/31-130-1-PB\%20(1).pdf>. Acesso em: 24 set. 2013.

MELO, H. P. de. Gênero e perspectiva regional na educação superior brasileira. In: RISTOFF, D. et al. Simpósio Gênero e Indicadores da Educação Superior Brasileira. Brasília: INEP, 2008.

MELO, H. P.; CASEMIRO, M. C. P. A ciência no feminino: uma análise da Academia Nacional de Medicina e da Academia Brasileira de Ciência. Revista Rio de Janeiro, n. 11, set.-dez. 2003. Disponível em: < http://www.forumrio. uerj.br/ documentos/revista_11/11-Hildete.pdf>. Acesso em: 06 maio 2014.

RISTOFF, D. A mulher na educação superior brasileira. In: et al. Simpósio Gênero e Indicadores da Educação Superior Brasileira. Brasília: INEP, 2008.

ROSSITER, M. Women Scientists in America: struggles and strategies to 1940. Baltimore: Johns Press, 1982. Disponível em: <http://books.google.com.br/ books?id=jJr6ZfkDbE4C\&printsec $=$ frontcover\&hl=pt-BR\&source $=$ gbs_ge_ summary_r\&cad $=0 \# \mathrm{v}=$ onepage $\& \mathrm{q} \& \mathrm{f}=$ false $>$. Acesso em: 03 mar 2014.

SAAVEDRA, L. Assimetrias de gênero nas escolhas profissionais. CIG, Lisboa, 2009. p. 121-130. Disponível em: <http://www.cig.gov.pt/wp-content/ uploads/2014/01/121_130_t3c_cap1_3_5.pdf>. Acesso em: 14 ago. 2013.

SANTANA, F. S.; PARENTE, T. G. Usina Hidrelétrica no Tocantins e sujeitos na construção da consciência jurídica: o reassentamento Córrego Prata em Porto Nacional (TO) Novos Cadernos NAEA,v. 16, n. 2, p. 121-148, jul-dez. 2013.

SCHIEBINGER, L. O feminismo mudou a ciência? Tradução de Raul Fiker, Bauru: EDUSC, 2001. 
SCOTT, J. W. Gênero: uma categoria útil de análise histórica. Tradução de Guacira Lopes Louro. Educação \& Realidade, Porto Alegre, v. 16, n. 2, p. 5-22, jul./dez. 1990.

TABAK, F. Sobre avanços e obstáculos. In: BRASIL. Presidência da República. Secretaria Especial de Políticas para as Mulheres. Pensando Gênero e Ciência: encontro nacional de núcleos e grupos de pesquisa. Brasília, 2006. p. 27-40.

TAVARES, I. A participação feminina na pesquisa: presença das mulheres nas áreas do conhecimento. In: RISTOFF, D. et al. Simpósio Gênero e Indicadores da Educação Superior Brasileira. Brasília: INEP, 2008.

VIANA, C. P. A feminização do magistério na educação básica e os desafios para a prática e a identidade coletiva docente. In: YANNOULAS, S. C. (Coord.). Trabalhadoras: análise da feminização das profissões e ocupações. Brasília: Editorial Abaré, 2013.

YANNOULAS, S. C. Mulheres e ciência. Série Anis, Brasília, n. 47, Letras Livres, p. 1-8, mar. 2007. Disponível em: <http://www.anis.org.br/serie/serie. cfm>. Acesso em: 06 mar. 2014. 


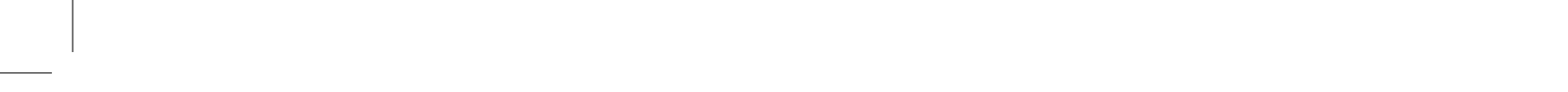

